\title{
Inhibiting Effect of a Green Corrosion Inhibitor Containing Jatropha Curcas Seeds Oil for Iron in an Acidic Medium
}

\author{
M. Zouarhi ${ }^{a}$, M. Chellouli ${ }^{a, *}$, S. Abbout ${ }^{a}$, H. Hammouch ${ }^{a}$, A. Dermaj ${ }^{a}$, S.O. \\ Said Hassane $^{b}$, P. Decaro ${ }^{c}$, N. Bettach ${ }^{a}$, N. Hajjaji ${ }^{a}$ and A. Srhiri ${ }^{d}$ \\ ${ }^{a}$ Laboratory of Materials Electrochemistry and Environment (LMEE), Department of \\ Chemistry, Faculty of Sciences, University Ibn Tofail, P.O. Box 133, 14000, Kenitra, Morocco \\ ${ }^{b}$ Technology and Faculty of Science, University of the Comoros, \\ P.O. Box 2585 Moroni, Comoros \\ ${ }^{c}$ Laboratory of Organic Synthesis, Department of Process Engineering, National School of \\ Engineers in Chemical and Technological Arts (ENSIACET-INP), Toulouse, France \\ ${ }^{d}$ Servichim Company, SARL, 1400 Kenitra, Morocco
}

Received January 23, 2017; accepted August 7, 2017

\begin{abstract}
The chemical composition of Jatropha curcas seeds oil was determined using chromatography gas (GC/MS) analysis after the esterification of fatty acids to methyl ester (FAME). The obtained results show that the average yield of Jatropha curcas seeds oil reached a maximum value of $50 \%$. The seeds oil fatty acids carbon chain was composed of palmitic, oleic and linoleic acids. The percentage of unsaturated fatty acids reached a value of $77 \%$. The new developed formulation containing Jatropha curcas seeds oil (labeled as JAC) was tested as a friendly iron corrosion inhibitor in an acidic medium by potentiodynamic polarization and Electrochemical Impedance Spectroscopy (EIS) techniques. The surface analysis was performed using Scanning Electron Microscopy (SEM). The electrochemical measurements show that the JAC formulation is a mixed type inhibitor. The obtained inhibition efficiency results increase with higher inhibitor concentrations, to attain a maximum value of $97 \%$ at $250 \mathrm{ppm}$. Furthermore, the protective effect is reinforced by increasing the immersion time and the rotation speed of the working electrode.
\end{abstract}

Keywords: corrosion, iron, Jatropha curcas oil, JAC formulation and acidic medium.

\section{Introduction}

Iron is the most abundant metal in the globe, long used in metallurgy such as weapons manufacture or jewelry, industries construction, and transports [1]. Nowadays, iron is the most commonly used metallic material in all industrial processes, due to its low cost.

\footnotetext{
* Corresponding author. E-mail address: mchellouli@gmail.com
} 
However, it is subject to corrosion phenomena that become critical, particularly in acidic media [2]. For this reason, many authors have proposed different steel corrosion mechanisms and techniques to study this phenomenon, and to develop protection systems against it $[3,4]$.

The use of corrosion inhibitors is one of the most profitable methods. Several scientific researchers are devoted to use natural products extracted from some aromatic herbs and medicinal plants as corrosion inhibitors; these natural products are called "environmental friendly corrosion inhibitors"[5], because they have effective ecological properties.

Jatropha curcas plant originates from Central America continent. It is a droughtresistant, perennial plant living up to 50 years, which has the capability to grow on marginal soils, and requires little irrigation, thus being a more sustainable choice than other vegetable oils [6-9].

$J$. c. seeds are composed of a kernel and a shell with an average ratio of 62.2 / 37.7. The kernel has higher crude protein (22-28\%) and oil contents (54-58\%) $[10,11]$.

The seeds oil residues can be used for soap production in cosmetics industry, and for supplying oils for biofuel [12]. $J$. $c$. produces renewable energy in the form of biodiesel, which emits $80 \%$ less $\mathrm{CO}_{2}, 100 \%$ less $\mathrm{SO}_{2}$, and has a higher flash point than fossil diesel fuel [13].

The aim of this study is to develop a new corrosion inhibitor formulation based on $J$. c. seeds oil to protect iron artifacts, which have a composition similar to archaeological iron in acidic solutions.

At first, we extracted the oil from $J$. $c$. seeds to determinate its fatty acids composition. Then, we investigated the preparation of a special formulation containing the extracted oil, and we studied the corrosion inhibition effect of this product by electrochemical tests and surface analysis techniques.

The inhibition efficiency was evaluated by stationary and transitory electrochemical measurements. In order to confirm our results, we carried out the surface analysis using SEM.

\section{Material and methods \\ Oil extraction}

$J$. c c seeds used in the present study come from the Comoros islands. The collected seeds were cleaned, separated from their hulls, and dried in ambient temperature, and then crushed to obtain the seeds powder, which later was dried in a drying oven at $50{ }^{\circ} \mathrm{C}$ during 24 hours, to eliminate any trace of water.

The obtained oil was extracted for 6 hours by a Soxhlet extractor apparatus using cyclohexane solvent, and it was purified by a rotary evaporator, then filtered and stored at $4{ }^{\circ} \mathrm{C}$.

\section{Fatty acid analysis}

Fatty acids were trans-esterified into methyl esters (FAME) [14], identified by gas chromatography (GC3900), CP- Select CB for FAME fused silica WCOT (50 m x $0.25 \mathrm{~mm} \times 0.25 \mu \mathrm{m}$ film thickness), and equipped with a flame 
ionization detector (FID). The flow rate of the carrier gas helium was 1.2 $\mathrm{mL} / \mathrm{min}$. The injector and FID temperatures were set at $250{ }^{\circ} \mathrm{C}$. The initial column temperature was programmed from $140{ }^{\circ} \mathrm{C}$, at $5{ }^{\circ} \mathrm{C} / \mathrm{min}$, to $180{ }^{\circ} \mathrm{C}$, being kept for $5 \mathrm{~min}$ at $180{ }^{\circ} \mathrm{C}$, and then from $45^{\circ} \mathrm{C} / \mathrm{min}$ until $250{ }^{\circ} \mathrm{C}$, being kept for $10 \mathrm{~min}$ at $250{ }^{\circ} \mathrm{C}$. Peaks were identified by comparing retention times with those of standard fatty acid methyl esters.

\section{Electrochemical measurements}

\section{Corrosive medium}

The corrosive solution was a simulated solution of acid rainwater (AR), prepared by the addition of $0.2 \mathrm{~g} / \mathrm{L} \mathrm{Na}_{2} \mathrm{SO}_{4}, 0.2 \mathrm{~g} / \mathrm{L} \mathrm{NaHCO} 3$ and $0.2 \mathrm{~g} / \mathrm{L} \quad \mathrm{NaCl}$ in distilled water, and maintained at $\mathrm{pH}=3.6$, by adding a few drops of sulfuric acid. This solution may correspond to acid rainwater in urban areas near the seaside, with a high degree of pollution (industrial atmosphere) [5, 15].

\section{Material}

The iron samples used in this study have the composition indicated in Table 1.

Table.1. Iron composition determined by EDS analysis [16].

\begin{tabular}{|c|c|c|c|c|c|c|}
\hline Elements & Si & Mn & C & P & S & Fe \\
\hline Weight (\%) & 0.201 & 0.519 & 0.157 & 0.007 & 0.009 & Balance \\
\hline
\end{tabular}

\section{Corrosion inhibitor}

The corrosion inhibitor contained $J$. $c$. seeds oil, prepared according to the formulation already patented in our laboratory [17], and was based on its fatty acids. To perform electrochemical measurements, a stock solution of $250 \mathrm{ppm}$ inhibitor concentration was prepared, and then diluted to different concentrations: 200, 150,100 and 50 ppm.

\section{Electrochemical methods}

For electrochemical measurements, we used a traditional cell with three electrodes: a saturated calomel (SCE) as reference electrode, a large platinum surface as counter electrode and, as working electrode, a cylindrical form coated in an impermeable resin, with a $1 \mathrm{~cm}^{2}$ contact surface with the corrosive medium. We used the rotating disk electrode (CTV 101) for the rotation speed tests. Before each experiment, the working electrode surface was polished with abrasive paper until 2000, rinsed with distilled water, degreased with acetone, and finally dried with hot propelled air.

Potentiodynamic and electrochemical impedance spectroscopy measurements were carried out by using a Bio-Logic (SP-200) apparatus connected to a computer, with a sweeping speed of $1 \mathrm{mV} / \mathrm{s}$, and $10 \mathrm{mV}$ of amplitude.

In the electrochemical impedance tests, the frequency spectrum range was extended from $100 \mathrm{KHz}$ to $10 \mathrm{mHz}$ at the open circuit potential (OCP). The electrolyte solution volume was $80 \mathrm{~mL}$. 


\section{Surface analysis}

The surface morphology was investigated by Scanning Electron Microscopy (SEM) using a Leica Stereoscan 440 electron microscope. SEM images were recorded after samples immersion for 24 hours in the AR solution, in the absence and presence of $250 \mathrm{ppm}$ of the JAC formulation.

\section{Results and discussion}

\section{Characterization of fatty acid composition}

The $J$. c. seeds used in this study contained $49.54 \%$ of oil. Oleic and linoleic acids were the principal fatty acids found in the oleaginous seeds. The fatty acids composition of $J$. $c$. oil is summarized and compared with results reported in literature.

Table 2. Fatty acid composition of $J$. $c$. seeds oil.

\begin{tabular}{|l|c|c|}
\hline \multirow{2}{*}{ Fatty acids } & \multicolumn{2}{|c|}{ Amounts of fatty acids (\%) } \\
\cline { 2 - 3 } & Present study & Literature [18] \\
\hline $\mathrm{C}_{16: 0}$ palmitic & 12.99 & $14.1-15.3$ \\
\hline $\mathrm{C}_{18: 0}$ stearic & 7.44 & $3.7-9.8$ \\
\hline $\mathrm{C}_{18: 1}$ oleic & 48.64 & $34.3-45.8$ \\
\hline $\mathrm{C}_{18: 2}$ linoleic & 28.37 & $29.8-42.2$ \\
\hline $\mathrm{C}_{18: 3}$ linoleinic & 0.24 & 0.3 \\
\hline $\mathrm{C}_{20: 0}$ arachidate & 0.24 & - \\
\hline
\end{tabular}

Table 2 shows that $J$. $c$. seeds oil contains high quantities of mono-unsaturated acids (oleic acid), and a moderate quantity of polyunsaturated acids (linoleic and linoleinic acids). The total of unsaturated fatty acids was around 77\%. This prevalence indicates that the oil is rich in unsaturated fatty acids.

\section{Electrochemical measurements}

\section{Concentration effect of JAC inhibitor}

Potentiodynamic polarization

The cathodic and anodic polarization curves of the iron substrate in the AR solution at $\mathrm{pH}=3.6$, without and with various concentrations of the JAC formulation, are presented in Fig. 1. Then, the cathodic and anodic polarization curves are separately plotted in Fig. 1a and Fig. 1b, respectively. The range of concentrations investigated in this work was from $50 \mathrm{ppm}$ to $250 \mathrm{ppm}$. All of these curves have been obtained after $30 \mathrm{~min}$ of immersion time in the corrosive medium, at corrosion potential, $\mathrm{E}_{\text {corr, }}$ and after performing the automatic ohmic drop compensation (ZIR).

The initial potential was stated at a slightly more positive potential of $\mathrm{E}_{\text {corr }}$ for the cathodic scans, and conversely, it was set at a slightly more negative value of $\mathrm{E}_{\text {corr }}$ for the anodic scans.

As shown in Fig.1a, the shape of the cathodic curves obtained without inhibitor showed a current plateau attributed to the oxygen diffusion process [19], indicating that the mass transport is an important factor which must be considered in the cathodic process [20], according to the following reaction [21]: 


$$
2 \mathrm{H}_{2} \mathrm{O}+\mathrm{O}_{2}+4 \mathrm{e}^{-} \rightarrow 4 \mathrm{OH}^{-}
$$

We noted that the corrosion potential, $\mathrm{E}_{\mathrm{corr}}$, value was $-538 \mathrm{mV} / \mathrm{SCE}$, in the inhibitor absence. However, in the inhibitor presence, the corrosion potential, value shifted towards a positive potential direction.
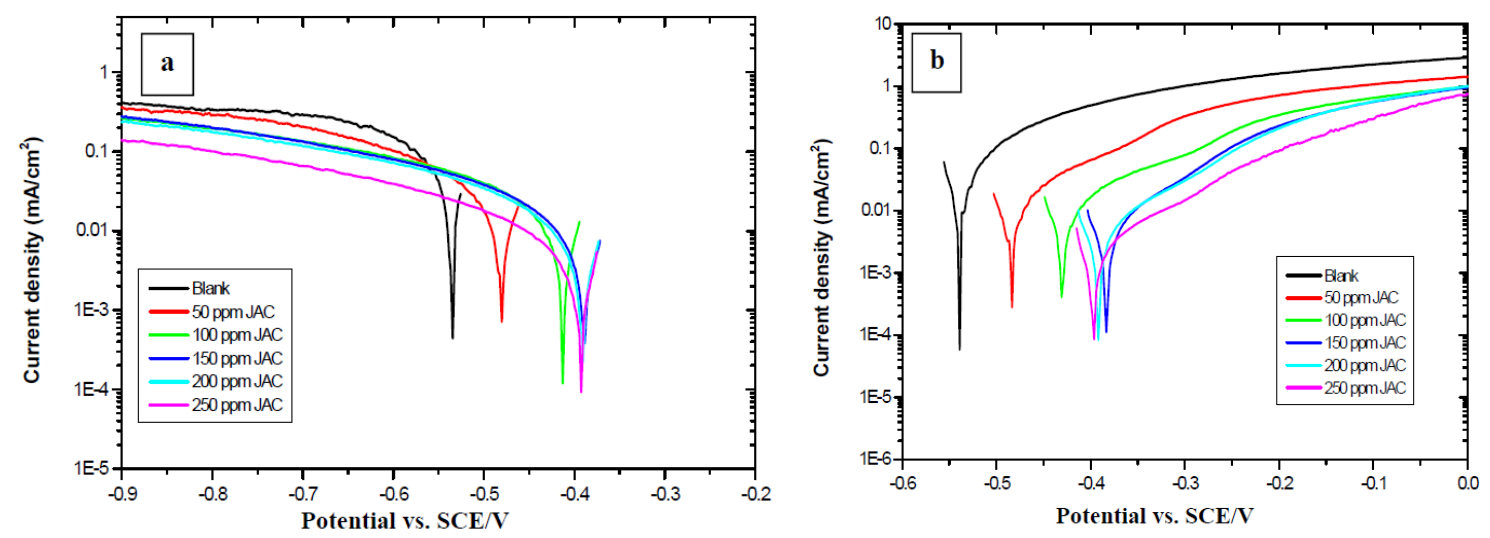

Figure 1. Potentiodynamic polarization curves of iron in the AR solution at different concentrations of the JAC formulation in the cathodic (a) and anodic (b) domains, respectively, after the automatic ohmic drop compensation (ZIR).

At $250 \mathrm{ppm}$ of the JAC formulation, the corrosion potential value became around $-396 \mathrm{mV} / \mathrm{SCE}$. This potential corresponds well to iron corrosion in the passive state, which may indicate that the JAC inhibitor has an anodic effect.

JAC addition was accompanied by a decrease in cathodic current density values, with the disappearance of the diffusion plateau obtained in the cathodic domain in the case of the blank essay. This is because the inhibitor addition leads to a change in the cathodic mechanism [20].

As shown in Fig.1b, in the anodic domain, we observe that the anodic current density value, in JAC absence, significantly increased at the vicinity of corrosion potential. Furthermore, in the high anodic overvoltage, the anodic current density value slightly increased in the studied domain.

In contrast, JAC addition to the AR solution was accompanied by a decrease in the anodic current density values.

In the anodic overvoltage, and for all JAC concentrations, we noted that the corrosion potential became more anodic and, also, that the current density increased compared to the blank essay.

This increase in the anodic current density was more pronounced over -300 $\mathrm{mV} / \mathrm{SCE}$ of the corrosion potential value. This evolution may be explained by the destruction of the inhibitor film formed at the corrosion potential, which can be due to the protection offered by the water oxidation reaction, that causes a local destruction of the film, and, consequently, the start of pitting corrosion.

Nevertheless, the presence of this film hinders pitting propagation; thus, the current density remains relatively low compared to that observed in the inhibitor absence [5].

The corrosion current density was determined by the EC-lab software, after diffusion correction, by using the following relation $[22,23]$ : 


$$
1 / \mathrm{I}=1 / \mathrm{I}^{*}+1 / \mathrm{I}_{\mathrm{L}}
$$

where $\mathrm{I}=$ current density at mixed process, $\mathrm{I}^{*}=$ corrected current density and $\mathrm{I}_{\mathrm{L}}$ $=$ limited current density.

The kinetic parameters of the iron electrode corrosion are summarized in Table 3.

Table 3. Kinetic parameters determined from polarization curves of the iron substrate in the AR solution, without and with various JAC concentrations.

\begin{tabular}{|c|c|c|c|c|c|}
\hline $\begin{array}{c}\text { JAC concentration } \\
(\mathrm{ppm})\end{array}$ & $\begin{array}{c}\mathbf{E}_{\text {corr }} \\
(\mathrm{mV} / \mathrm{sCE})\end{array}$ & $\begin{array}{c}\mathbf{I}_{\text {corr }} \\
\left(\mu \mathrm{A} / \mathbf{c m}^{2}\right)\end{array}$ & $\begin{array}{c}-\beta c \\
\left(\mathbf{m V d e c}^{-1}\right)\end{array}$ & $\begin{array}{c}\boldsymbol{\beta a} \\
\left.(\mathbf{m V d e c})^{-1}\right)\end{array}$ & $\begin{array}{l}\text { IE } \\
(\%)\end{array}$ \\
\hline Blank & -538 & 73.24 & 211 & 154 & --- \\
\hline 50 & -483 & 17.61 & 129 & 148 & 75.96 \\
\hline 100 & -430 & 9.97 & 114 & 123 & 86.39 \\
\hline 150 & -382 & 5.93 & 113 & 109 & 91.90 \\
\hline 200 & -391 & 5.08 & 114 & 116 & 93.06 \\
\hline 250 & -396 & 2.34 & 93 & 118 & 96.80 \\
\hline
\end{tabular}

As it is shown in Table 3, the current density value decreased with increased inhibitor concentrations, and simultaneously, the inhibition efficiency increased with higher JAC concentrations, reaching a value of $97 \%$ at $250 \mathrm{ppm}$.

By analyzing the polarization curves and kinetic parameters, we can conclude that the JAC formulation is a mixed type inhibitor, which affects both cathodic and anodic behaviors. This good inhibiting effect of the JAC formulation may be attributed to its adsorption onto the electrode surface, which can form a film that acts as a barrier layer on the iron surface, minimizing the contact area with the corrosive medium, and hindering metal oxidation.

\section{Electrochemical impedance spectroscopy}

Electrochemical impedance spectroscopy (EIS) is a useful and non-destructive experimental technique, which can simulate the real electrochemical behavior in the electrode/solution interface, and precisely determine the kinetic parameters of the studied system [24, 25]. Fig. 2 gives the EIS diagrams in the Nyquist plots of the iron substrate.

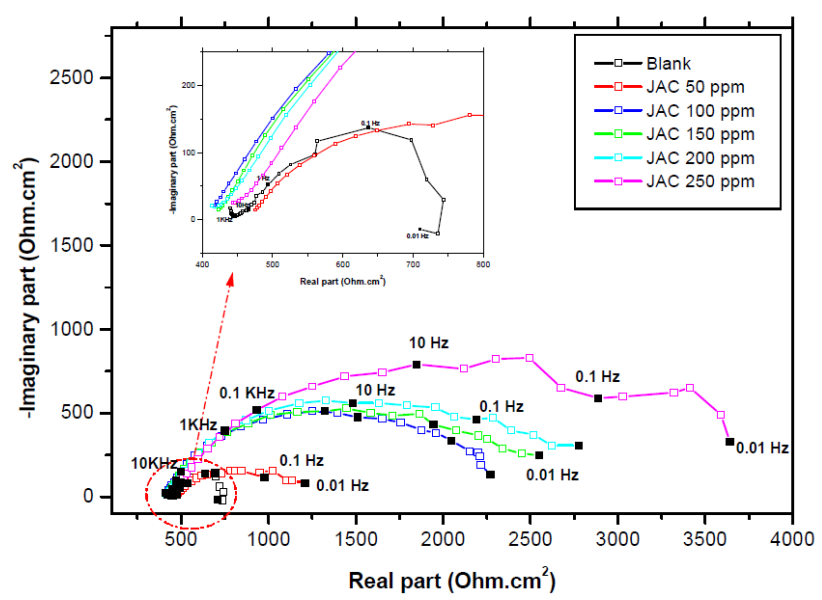

Figure 2. Nyquist plots recorded for the iron substrate in the AR solution, without and with the addition of different concentrations of the JAC formulation. 
The impedance spectra were started after 30 min of immersion time, in the AR solution, without and with the JAC inhibitor, to avoid significant changes in the open circuit potential (OCP).

The impedance spectra in the JAC formulation absence displayed two capacity loops: $\left(\mathrm{R}_{\mathrm{HF}}, \mathrm{C}_{\mathrm{HF}}\right)$ in the high frequencies, and $\left(\mathrm{R}_{\mathrm{LF}}, \mathrm{C}_{\mathrm{LF}}\right)$ in the beginning of the inductive loop in the low frequencies [26], comparatively to a study already published [20].

The inhibition efficiency (IE \%) was calculated using the following equation:

$$
I E(\%)=\frac{R_{p}^{i}-R_{p}}{R_{p}^{i}} \times 100
$$

where $R_{p}^{i}$ and $R_{p}$ are the polarization resistance values, in the inhibitor presence and absence, respectively.

The JAC formulation addition at various concentrations has removed the inductive behavior of the iron substrate in the AR solution.

On the one hand, we noted a change in the loops shape and size; on the other hand, as it can be observed from Fig. 2, the impedance modulus notably increased in the JAC formulation presence.

In the studied frequency range, the system could be described by the corresponding structural model of the interface, without and with the JAC inhibitor, as shown in Fig. 3.

In the equivalent electrical circuit (EEC), according to the impedance spectrum in the inhibitor absence, the solution resistance is $R_{s}$; the resistances in the high and low frequencies are $\mathrm{R}_{\mathrm{HF}}$ and $\mathrm{R}_{\mathrm{RF}}$, respectively, and the inductance is $\mathrm{L}$ (see Fig. 3a). However, in the JAC inhibitor presence, the EEC showed the absence of the inductive element in the impedance spectrum. While $R_{f}$ refers to the film resistance, due to the ionic conduction through the inhibitor layer, $R_{t}$ is the charge transfer resistance, and $\left(\mathrm{C}_{\mathrm{f}}-\mathrm{C}_{\mathrm{dl}}\right)$ present the film capacitance due to the electronic insulating property, and the double layer capacitance at the metal electrolyte interface, respectively (see Fig. 3 b).

a)

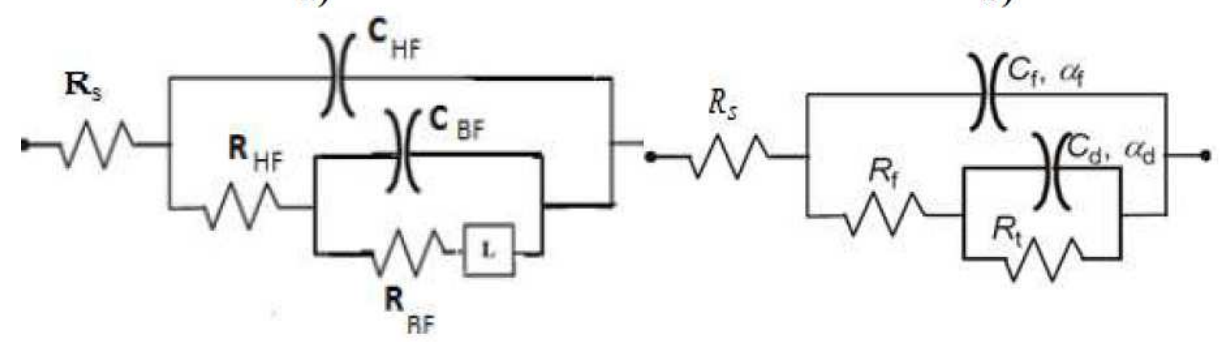

Figure 3. Scheme of the equivalent electrical circuit used to fit EIS data to the iron substrate. a) In the blank solution (AR). b) In the JAC inhibitor presence.

Electrochemical parameters derived from the EIS diagrams associated to Fig. 3 are shown in Table 4.

From Table 4 it is found that the transfer resistance, $R_{t}$, values increased with an increase in the JAC formulation concentrations, whereas the double layer 
capacitance, $\mathrm{C}_{\mathrm{dl}}$, values decreased; this decrease was due to the adsorption of the JAC inhibitor onto the metal surface [5].

Table 4. Electrochemical data derived from EIS spectra for iron substrate in the AR solution at different concentrations of the JAC formulation

\begin{tabular}{|c|c|c|c|c|c|c|c|c|}
\hline Blank & $\begin{array}{c}\mathbf{R}_{\mathbf{s}} \\
\left(\mathbf{o h m} \cdot \mathbf{c m}^{2}\right)\end{array}$ & \multicolumn{2}{|c|}{$\begin{array}{c}\mathrm{C}_{\mathrm{HF}} \\
\left(\mu \mathrm{F} / \mathrm{cm}^{2}\right)\end{array}$} & $\begin{array}{c}\mathbf{R}_{\mathrm{HF}} \\
\left(\mathbf{o h m} . \mathrm{cm}^{2}\right)\end{array}$ & $\begin{array}{c}\mathrm{C}_{B F} \\
\left(\mu \mathrm{F} / \mathbf{c m}^{2}\right)\end{array}$ & $\begin{array}{c}\mathbf{R}_{\mathrm{BF}} \\
\left(\mathbf{o h m} \cdot \mathbf{c m}^{2}\right)\end{array}$ & \multicolumn{2}{|c|}{$\underset{(\text { ohm.cm }}{\mathbf{R}_{\mathbf{p}}}$} \\
\hline AR soluti & 433 & 82. & & 164 & 702. & 203 & 367 & \\
\hline $\begin{array}{c}\text { JAC } \\
\begin{array}{c}\text { Concentrations } \\
(\mathbf{p p m})\end{array}\end{array}$ & $\begin{array}{c}\mathbf{R}_{\mathrm{s}} \\
\left(\mathbf{o h m} . \mathrm{cm}^{2}\right)\end{array}$ & $\begin{array}{c}\mathbf{C}_{\mathbf{f}} \\
\left(\mu \mathrm{F} / \mathrm{cm}^{2}\right)\end{array}$ & & $\begin{array}{c}\mathbf{R}_{\mathrm{f}} \\
\left.\mathbf{h m . \mathrm { cm } ^ { 2 }}\right)\end{array}$ & $\begin{array}{c}\mathrm{C}_{\mathrm{dl}} \\
\left(\mu \mathrm{F} / \mathrm{cm}^{2}\right)\end{array}$ & $\begin{array}{c}\mathbf{R}_{\mathbf{t}} \\
\left(\mathbf{o h m} . \mathrm{cm}^{2}\right)\end{array}$ & $\begin{array}{c}\mathbf{R}_{\mathbf{p}} \\
\left(\mathbf{o h m} . \mathrm{cm}^{2}\right)\end{array}$ & $\begin{array}{l}\text { IE } \\
(\%)\end{array}$ \\
\hline 50 & 459 & 8.61 & & 219 & 625.64 & 729 & 948 & 60.7 \\
\hline 100 & 376 & 4.97 & & 379 & 188.33 & 1658 & 2037 & 82.02 \\
\hline 150 & 381 & 4.84 & & 390 & 169.32 & 1848 & 2238 & 83.63 \\
\hline 200 & 397 & 4.77 & & 395 & 156.43 & 2000 & 2395 & 84.71 \\
\hline 250 & 415 & 3.78 & & 474 & 103.04 & 3036 & 3510 & 89.56 \\
\hline
\end{tabular}

The film capacitance, $\mathrm{C}_{\mathrm{f}}$, has also decreased with an increase in the JAC formulation concentration $\left(\mathrm{C}_{\mathrm{f}}<10 \mu \mathrm{F} / \mathrm{cm}^{2}\right)$ [20, 27, 28, 29], which was probably due to the formation of a protective layer on the electrode surface [20,5]; then, the inhibition efficiency reached a value of $90 \%$ at 250 ppm, after 30 minutes immersion time.

\section{Rotating disc effect of the iron electrode}

Case of the blank solution

The use of the rotating disc electrode is one of the essential methods to determine the mechanism controlling the electrolyte/metal interface process.

The cathodic and anodic polarization curves of the iron substrate in the AR solution at $\mathrm{pH}=3.6$, after $30 \mathrm{~min}$ of immersion time, at different rotation speeds, are reported in Fig. 4.

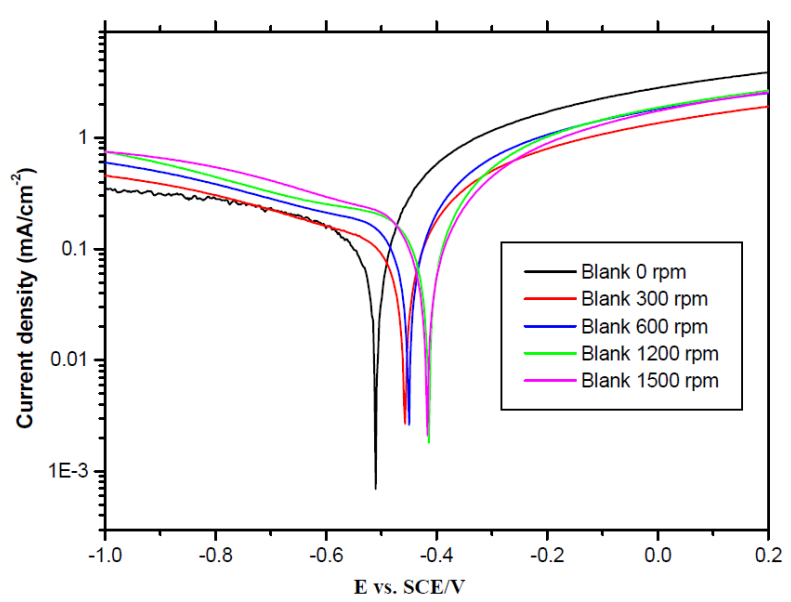

Figure 4. Potentiodynamic polarization curves of the iron substrate in an AR solution $(\mathrm{pH}=3.6)$ at various rotation speeds, after the automatic ohmic drop compensation (ZIR). 
As shown in Fig. 4, the increase in the rotation speed led to a displacement of the corrosion potential, in the positive direction. The increase in the current density value, $I_{\text {corr }}$, from $75.57 \mu \mathrm{A} / \mathrm{cm}^{2}$ at $0 \mathrm{rpm}$, to a value of $100.42 \mu \mathrm{A} / \mathrm{cm}^{2}$ at 1500 rpm, can be explained by the increase in the amount of dissolved oxygen on the electrode surface [30].

In the one hand, in the cathodic domain, we observed an increase in the bearing height current density with an increased rotation speed of the working electrode. This result is in accordance with the diffusion control of the dissolved oxygen reduction [31 and 32]. In the other hand, we noticed that, in the anodic domain, the kinetics reaction corresponds to the metal dissolution [33]. Furthermore, the polarization curves are relatively parallel for all rotation speeds.

At the potential $0 \mathrm{mV} / \mathrm{SCE}$, we noted that the current density value decreased two times when we passed from 0 rpm to $300 \mathrm{rpm}$.

These results indicate that the formation of a prohibitive layer substantially depends on the rotating electrode speeds, and it is limited by the hydrodynamic conditions [31].

The derived parameters obtained from the potentiodynamic polarization curves are summarized in Table 5.

Table 5. Kinetic parameters from current-potential curves of the iron electrode in the AR solution with different rotation speeds.

\begin{tabular}{|c|c|c|c|c|}
\hline $\begin{array}{c}\text { Rotation speeds } \\
(\mathbf{r p m})\end{array}$ & $\begin{array}{c}\mathbf{E}_{\text {corr }} \\
(\mathbf{m V / E C s})\end{array}$ & $\begin{array}{c}\mathbf{I}_{\mathbf{c o r r}} \\
\left(\boldsymbol{\mu} \mathbf{A} / \mathbf{c m}^{2}\right)\end{array}$ & $\begin{array}{c}\mathbf{- \beta c} \\
\left(\mathbf{m V d e c}^{-1}\right)\end{array}$ & $\begin{array}{c}\boldsymbol{\beta a} \\
\left(\mathbf{m V d e c}^{-\mathbf{1}}\right)\end{array}$ \\
\hline 0 & -512 & 75.57 & 271 & 103 \\
\hline 300 & -460 & 75.88 & 344 & 157 \\
\hline 600 & -448 & 87.68 & 261 & 127 \\
\hline 1200 & -414 & 97.01 & 270 & 143 \\
\hline 1500 & -418 & 100.42 & 278 & 176 \\
\hline
\end{tabular}

For better understanding the nature of the diffusion process, we have plotted the current density values variation as a function of the square root of the electrode rotation speeds $\left(\mathrm{I}=\mathrm{f}\left(\mathrm{w}^{1 / 2}\right)\right)$ [32]. The obtained results at different cathodic potential values $(-600,-700,-800$ and $-900 \mathrm{mV} / \mathrm{SCE})$ are shown in Fig. 5.

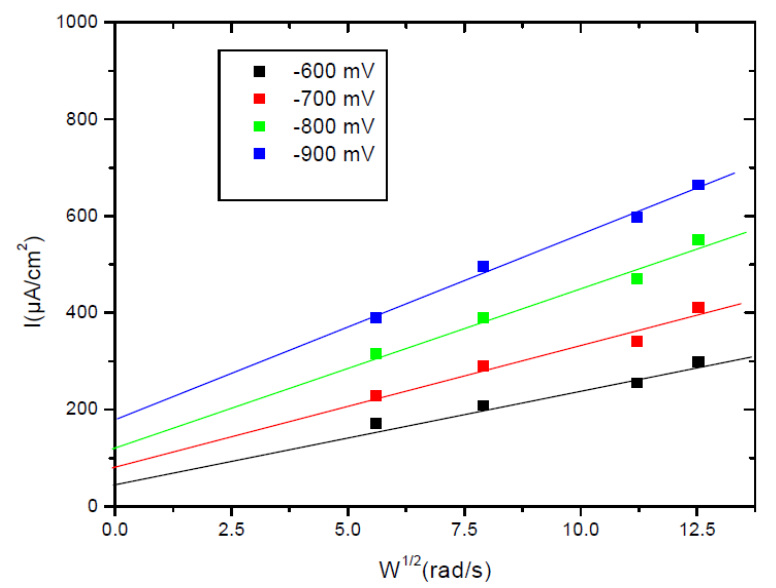

Figure 5. Evolution of the cathodic current density at various rotation speeds. 
As shown in Fig. 5, we can observe that the current density values linearly increase with the rotation speed square root. This result indicates that the cathode kinetics in the potential range is only controlled by the transport process in the interface electrode/solution [32 and 33].

The difference in the current density values observed in the studied potential areas at different rotational speeds can be explained by the presence of an oxidation products layer [34] on the electrode surface, which blocks a few cathode active sites and minimizes the contact surface between metal and solution. However, this oxide layer is brittle, and destructible.

We also noted that the fitting plots were not passed on the origin of the axis. This confirms the existence of two components in the global current density: $I_{d}$ is the diffusional component and $\mathrm{A}$ is the non-diffusional component, evaluated in the ordinate at the origin of the axis, according to the following relationship.

$$
\mathrm{I}=\mathrm{I}_{\mathrm{d}}+\mathrm{A}
$$

This relationship indicates that the interfacial reaction is governed by two different processes. This behavior leads to several hypotheses [35], which can be confirmed by the plot trace $\left(\mathrm{I}_{\mathrm{L}}^{-1}=\mathrm{f}\left(\mathrm{w}^{-1 / 2}\right)\right.$, where $\mathrm{I}_{\mathrm{L}}$ is the limit diffusion current density, given by the Levich relationship [36]:

$$
\mathrm{I}_{\mathrm{L}}=0.62 \mathrm{n} \mathrm{F} \mathrm{S} \mathrm{CO} \times \mathrm{DO}^{2 / 3} v^{-1 / 6} \mathrm{w}^{1 / 2}
$$

where $n$ is the number of electrons $(n=4), F$ is the Faraday constant $(F=96485 C$ $/ \mathrm{mol}), \mathrm{S}$ is the electrode surface area $\left(1 \mathrm{~cm}^{2}\right), \mathrm{C}_{\mathrm{O} 2}$ is the oxygen concentration in the bulk, which is usually taken as $0.2 \mathrm{~mol} / \mathrm{m}^{3}$ [37], $\mathrm{D}_{\mathrm{O} 2}$ is the oxygen diffusion coefficient, $v$ is the kinematic viscosity $\left(0.82 \times 10^{-6} \mathrm{~m}^{2} / \mathrm{s}\right)$ and $\mathrm{w}^{1 / 2}$ is the square root of the rotation speed $(\mathrm{rad} / \mathrm{s})$.

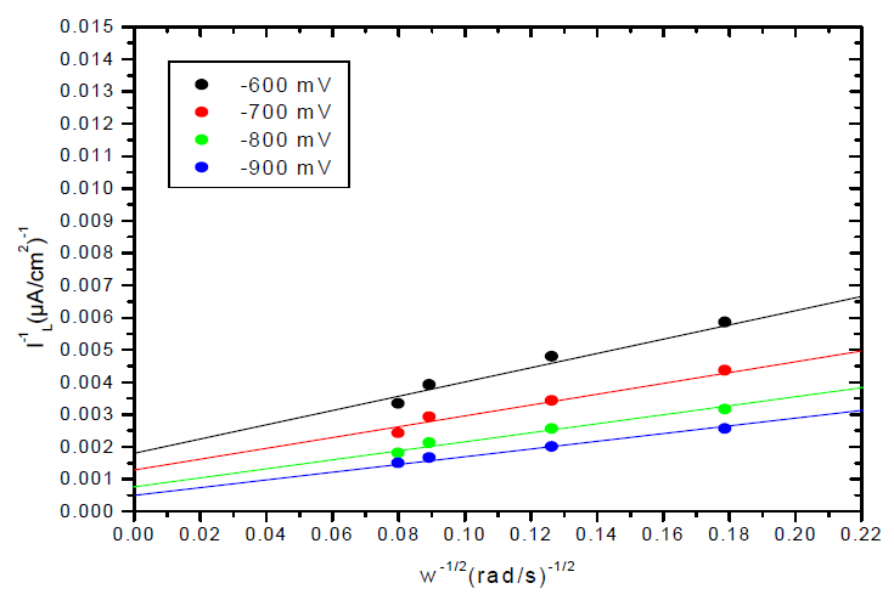

Figure 6. Koutecky-Levich plot for experimental conditions.

The fitting plots obtained in Fig. 6 are straight lines which are not passed on the origin of the axis; therefore, we confirmed the mixed activation-diffusion kinetics [33]. 
These results show that the cathodic current density controlled by the oxygen reduction at the interface electrode/solution [38] confirms a Koutecky-Levich relationship [33].

The impedance diagrams of the iron substrate in the AR solution $(\mathrm{pH}=3.6)$ at different rotation speeds are given in Fig. 7.

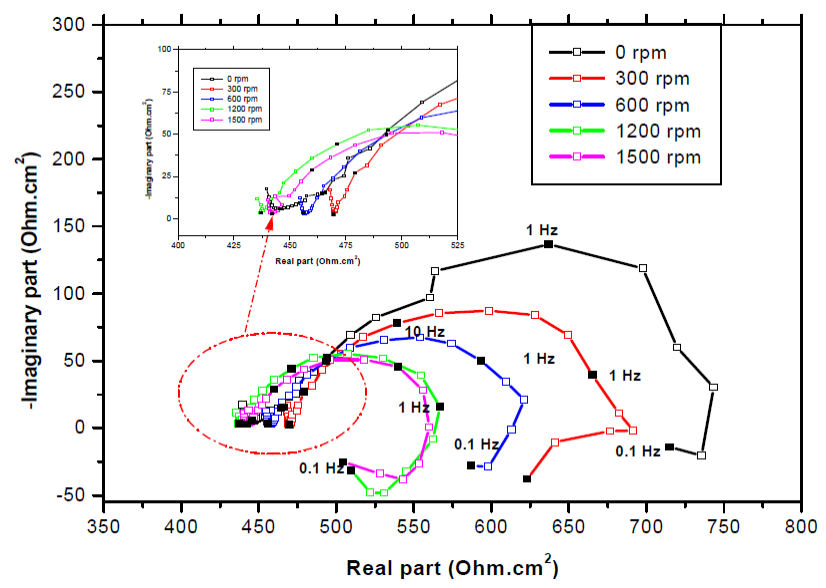

Figure 7. Recorded Nyquist plots of the iron substrate in the AR solution $(\mathrm{pH}=3.6)$ at various rotation speeds.

As shown in Fig. 7, the loop size was reduced when the rotation speeds were raised from $0 \mathrm{rpm}$ to $1500 \mathrm{rpm}$. This result reveals that the diffusion occurs in the interfacial process at the corrosion potential.

In the low frequencies, the inductive loops become more marked; this inductive effect may be due to the desorption of $\mathrm{H}^{+}$ions and salts ions present in the solution [23 and 39], or to the re-dissolution of the passivity surface [40].

Case in the JAC formulation presence

The inhibiting effect of the JAC inhibitor was evaluated at different rotation speeds of the iron electrode in the same experimental conditions without inhibitor.

The cathodic and anodic polarization curves of the iron substrate in the AR solution containing $250 \mathrm{ppm}$ of the JAC formulation, at different rotation speeds after $30 \mathrm{~min}$ of immersion time at the corrosion potential, are given in Fig. 8.

As shown in this figure, the polarization curves in the cathodic part have the same shapes at all rotation speeds. We also noted that, in the cathodic domain, the polarization curves were not affected by the rotation speeds, taking into account the sensitivity limits of the apparatus, and the experimental margin of error. Moreover, in the anodic domain, we observed that the passivation bearing became more marked with the increase in the rotation speeds.

Additionally, the current density significantly increased at a potential value of $80 \mathrm{mV} / \mathrm{SCE}$. This can be attributed to the desorption of the protector layer formed by the inhibitor.

The electrochemical parameters derived from these curves were determined by the EC- lab program. The obtained results are summarized in Table 6. 


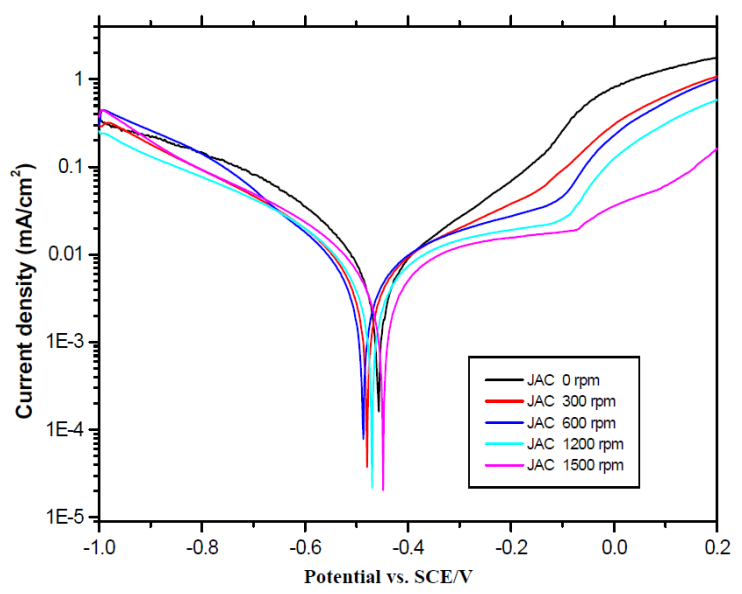

Figure 8. Potentiodynamic polarization curves of the iron substrate in the AR solution containing $250 \mathrm{ppm}$ concentration of the JAC inhibitor, at various rotation speeds, after the automatic ohmic drop compensation (ZIR).

Table 6. Kinetic parameters obtained from polarization curves of the iron substrate in the AR solution, in the presence of $250 \mathrm{ppm}$ of the JAC formulation at different rotation speeds.

\begin{tabular}{|c|c|c|c|c|c|}
\hline $\begin{array}{c}\text { Rotation speeds } \\
(\mathrm{rpm})\end{array}$ & $\begin{array}{c}\mathbf{E}_{\mathbf{c o r r}} \\
(\mathrm{mV} / \mathrm{ECS})\end{array}$ & $\begin{array}{c}\mathbf{I}_{\mathbf{c o r r}} \\
\left(\mu \mathrm{A} / \mathrm{cm}^{2}\right)\end{array}$ & $\begin{array}{c}-\boldsymbol{\beta c} \\
\left(\mathrm{mVdec}^{-1}\right)\end{array}$ & $\begin{array}{c}\boldsymbol{\beta a} \\
\left(\mathrm{mVdec}^{-1}\right)\end{array}$ & $\begin{array}{c}\mathbf{I E} \\
(\%)\end{array}$ \\
\hline 0 & -457 & 2.51 & 97 & 111 & 96.68 \\
\hline 300 & -481 & 2.29 & 106 & 131 & 96.98 \\
\hline 600 & -486 & 2.18 & 107 & 132 & 97.51 \\
\hline 1200 & -471 & 1.92 & 109 & 137 & 98.02 \\
\hline 1500 & -449 & 1.77 & 110 & 140 & 98.21 \\
\hline
\end{tabular}

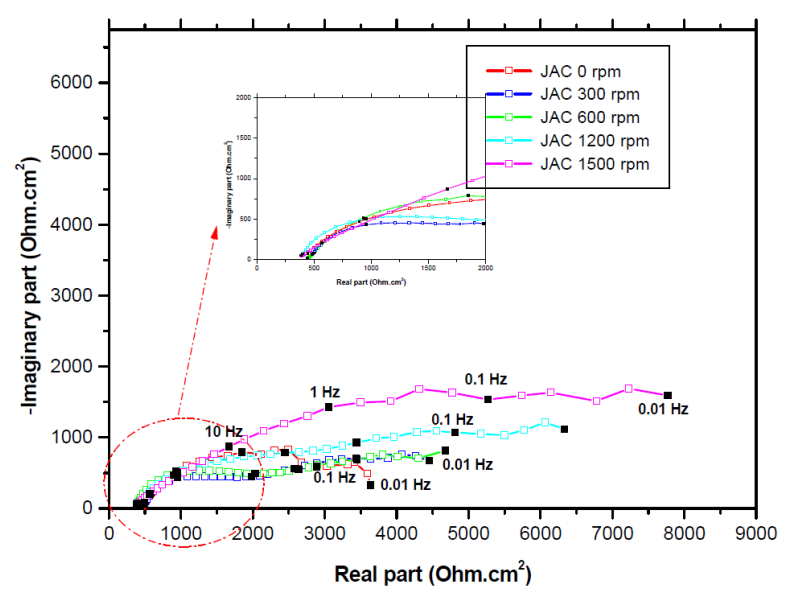

Figure 9. Impedance diagrams of the iron substrate in the AR solution, at $250 \mathrm{ppm}$ of the JAC formulation, at various rotation speeds.

As reported in Table 6, we noted that the current density values decreased with an increase in the rotation speeds at $250 \mathrm{ppm}$ concentration of the JAC inhibitor, improving its inhibition efficiency, which also happened in the blank solution $(\mathrm{pH}=3.6)$. 
From the inhibition efficiency values, we noted an insignificant change, even lesser when doubling the rotation speeds, reaching $98 \%$ at $1500 \mathrm{rpm}$.

For better understanding the involved reaction mechanisms, Fig. 9 represents the rotation speeds effect on the impedance spectra at the potential corrosion, at 250 ppm concentration of the JAC formulation.

Table 7. Electrochemical data derived from EIS spectra of the iron substrate in the AR solution containing $250 \mathrm{ppm}$ concentration of the JAC formulation, at different rotation speeds.

\begin{tabular}{|c|c|c|c|c|c|c|}
\hline $\begin{array}{c}\text { Rotation } \\
\text { speeds (rpm) }\end{array}$ & $\begin{array}{c}\mathbf{R}_{\mathbf{s}} \\
\left(\mathrm{Ohm} \cdot \mathrm{cm}^{2}\right)\end{array}$ & $\begin{array}{c}\mathbf{C}_{\mathbf{f}} \\
\left(\mu \mathrm{F} / \mathrm{cm}^{2}\right)\end{array}$ & $\begin{array}{c}\mathbf{R}_{\mathbf{f}} \\
\left(\mathrm{Ohm} \cdot \mathrm{cm}^{2}\right)\end{array}$ & $\begin{array}{c}\mathbf{C}_{\mathbf{d l}} \\
\left(\mu \mathrm{F} / \mathrm{cm}^{2}\right)\end{array}$ & $\begin{array}{c}\mathbf{R}_{\mathbf{t}} \\
\left(\mathrm{Ohm} \cdot \mathrm{cm}^{2}\right)\end{array}$ & $\begin{array}{c}\mathbf{R}_{\mathbf{p}} \\
\left(\mathrm{Ohm} \cdot \mathrm{cm}^{2}\right)\end{array}$ \\
\hline 0 & 415 & 3.78 & 474 & 103.04 & 3036 & 3510 \\
\hline 300 & 439 & 0.303 & 1288 & 91.36 & 5068 & 6356 \\
\hline 600 & 370 & 0.300 & 1301 & 81.99 & 5647 & 6948 \\
\hline 1200 & 378 & 0.200 & 1952 & 67.84 & 6824 & 8776 \\
\hline 1500 & 361 & 0.186 & 2102 & 54.64 & 8472 & 10574 \\
\hline
\end{tabular}

From the electrochemical impedance spectra, we can distinguish two capacitive loops. In the low frequencies, the capacitive loop can be attributed to the film formation. The former became more distinct by the increase in the rotation speeds; at rotation speed values higher than $600 \mathrm{rpm}$, we noticed an overlap of the two capacitive loops, which then became less distinct.

Furthermore, the size of the capacitive loops increased with higher rotation speeds, and we noted a significant increase in the polarization resistance value, $\mathrm{R}_{\mathrm{p}}$.

The electrochemical parameters associated to the EIS diagrams, by using the experimental fitting Ec-Lab program, are given in Table 7.

From Table 7, we can observe that the value of the capacitance film, $\mathrm{C}_{\mathrm{f}}$, decreased with higher rotation speeds. This may be due to the enhancement of the protector layer formed by the JAC inhibitor on the electrode surface.

\section{Immersion time effect}

The evolution of the impedance diagrams in the AR medium containing $250 \mathrm{ppm}$ of the JAC inhibitor, measured at corrosion potential, and recorded for different immersion times, is reported in Fig. 10.

As it can be seen in Fig.10, at the impedance diagrams in the Nyquist plot, the loops become larger with the immersion time; in addition, the capacitive loops maintained the same shape after 30 min of immersion time. The polarization resistance, $R_{p}$, considerably increased with higher immersion times.

In the one hand, the initial value of the polarization resistance is $3.61 \mathrm{k} \Omega . \mathrm{cm}^{2}$ after $30 \mathrm{~min}$ of immersion time; it increased up to $5.17,9.01$ and $12.51 \mathrm{k} \Omega . \mathrm{cm}^{2}$ after 4, 18 and 24 hours of immersion time, respectively. On the other hand, the film capacitance, $\mathrm{C}_{\mathrm{f}}$, decreases with the immersion time, and this evolution can be explained by the blocking ions on the electrode surface.

The electrochemical impedance parameters derived from these investigations are given in Table 8. 


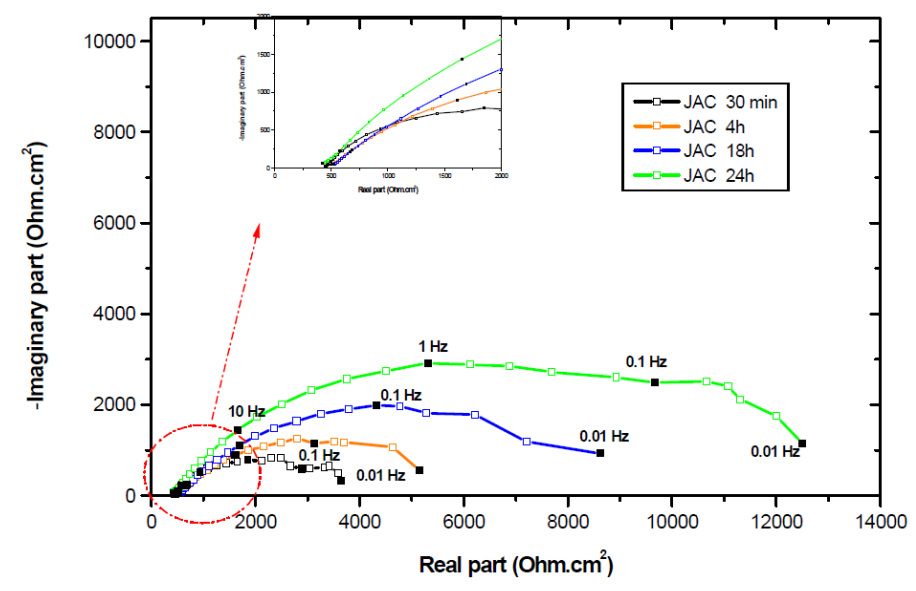

Figure 10. EIS spectra of the iron electrode in the AR solution containing $250 \mathrm{ppm}$ of the JAC formulation at different immersion times.

Table 8. Electrochemical impedance parameters determined from the Nyquist plot of the iron electrode in the AR solution containing $250 \mathrm{ppm}$ of the JAC inhibitor at different immersion times.

\begin{tabular}{|c|c|c|c|c|c|c|}
\hline Immersion time & $\begin{array}{c}\mathbf{R}_{\mathbf{s}} \\
\left(\mathrm{Ohm} \cdot \mathrm{cm}^{2}\right)\end{array}$ & $\begin{array}{c}\mathbf{C}_{\mathbf{f}} \\
\left(\mu \mathrm{F} / \mathrm{cm}^{2}\right)\end{array}$ & $\begin{array}{c}\mathbf{R}_{\mathbf{f}} \\
\left(\mathrm{Ohm} \cdot \mathrm{cm}^{2}\right)\end{array}$ & $\begin{array}{c}\mathbf{C}_{\mathbf{d l}} \\
\left(\mu \mathrm{F} / \mathrm{cm}^{2}\right)\end{array}$ & $\begin{array}{c}\mathbf{R}_{\mathbf{t}} \\
\left(\mathrm{Ohm} \cdot \mathrm{cm}^{2}\right)\end{array}$ & $\begin{array}{c}\mathbf{R}_{\mathbf{p}} \\
\left(\mathrm{Ohm} \cdot \mathrm{cm}^{2}\right)\end{array}$ \\
\hline $30 \mathrm{~min}$ & 415 & 3.78 & 474 & 103.04 & 3036 & 3510 \\
\hline $4 \mathrm{~h}$ & 441 & 3.22 & 866 & 72.61 & 4301 & 5167 \\
\hline $18 \mathrm{~h}$ & 449 & 2.05 & 2014 & 44.68 & 6998 & 9012 \\
\hline $24 \mathrm{~h}$ & 448 & 1.65 & 2501 & 21.07 & 10012 & 12513 \\
\hline
\end{tabular}

The results presented in Table 8 reveal that the JAC inhibitor acts as a good protecting barrier for the iron substrate in the AR medium, and its effect is enhanced by the immersion time.

\section{Surface analysis (SEM)}

The evaluation of the iron surface with the best inhibitor concentration is obtained by SEM analysis. The micrographs carried out in the JAC formulation absence and presence are given in Fig 11.
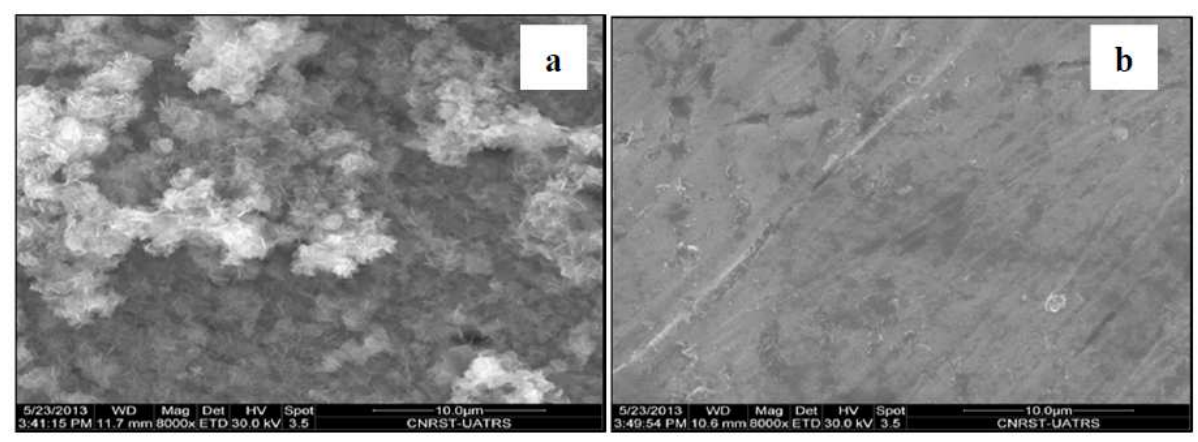

Figure 11. SEM micrographs: a) iron surface in the AR solution $(\mathrm{pH}=3.6)$ and $\mathbf{b})$ with $250 \mathrm{ppm}$ of the JAC inhibitor, after $24 \mathrm{~h}$ of immersion time. 
In the inhibitor absence (see Fig. 11a), the metal surface is heavily corroded, becoming rough and uneven. Moreover, we can observe the corrosion products deposit.

However, in the inhibitor presence (see Fig. 11b), the metal surface becomes more uniform and smooth, probably due to the adsorption of the JAC formulation molecules onto the iron surface, forming a protective layer.

\section{Conclusion}

The JAC formulation based on the extracted oil from Jatropha curcas seeds has a good protective effect against the iron substrate corrosion in the acidic rainwater (AR) medium. The protective effect was confirmed by stationary and transitory electrochemical measurements. Both approaches indicate that the JAC inhibitor adsorption onto the iron metal surface leads to the formation of a protective layer on the latter.

Potentiodynamic polarization showed that the JAC formulation acts as a mixed type inhibitor. The best inhibition efficiency reached a value of $97 \%$ at $250 \mathrm{ppm}$ concentration.

The protective effect of the JAC formulation is reinforced by higher rotation speeds and immersion times, leading to a decrease in the capacitance film value, and to an increase in the polarization resistance values. These results were confirmed by the SEM micrographs.

These first promising results encourage us to apply our JAC formulation in the conservation of iron archaeological objects exposed in museums.

\section{Acknowledgements}

We are so grateful for the effective support of the Servichim Kenitra Company, Morocco, and the collaboration of the Laboratory of Organic Synthesis, Department of Process Engineering, National School of Engineers in Chemical and Technological Techniques (ENSIACET-INP), Toulouse, France.

\section{References}

1. Hollner S. Développement de nouveaux traitements de protection a base d'acide carboxylique pour la conservation d'objets en fer du patrimoine culturel. thèse de l'UHP Nancy I. Nancy; 2009.

2. Hamdy A, El-Gendy NSh. Egyptian J Petrol. 2013;22:17.

3. Roberge PR. Handbook of Corrosion Engineering. New York: Mc GrawHill; 2000.

4. Rani BEA, Basu BBJ. Int J Corros. 2012;2012: Article ID 380217.

5. Hammouch H, Dermaj A, Chebabe D, et al. Anal Bioanal Electrochem. 2013;5:236.

6. National Oilseeds \& Vegetable Oils Development (NOVOD) Board 2007, Jatropha. An alternate source for biodiesel. Available from http://www.novodboard.com. 
7. National Oil seeds \& Vegetable Oils Development (NOVOD) Board. 2008. $3^{\text {rd }} \mathrm{R} \quad \& \quad \mathrm{D}$ report on tree borne oil seeds 2007-2008. http://www.novodboard.com.

8. Altenburg $\mathrm{T}$, Dietz $\mathrm{H}$, Hahl $\mathrm{M}$, et al. Biodiesel in India. Value chain organisation and policy options for rural development. Bonn: German Development Institute; 2009.

9. Reubens B, Achten WMJ, Maes WH, et al. J Arid Environ. 2011;75:201.

10. Makkar HPS, Aderibigbe AO, Becker K. Food Chem. 1998;62:207.

11. Carels N, Sujatha M, Bahadur B, editors. Jatropha, Challenges for a New Energy Crop. Volume 1: Farming, Economics and Biofuel. New York: Springer; 2012.

12. Poteet MD. Biodiesel Crop Implementation in Hawaii. The State of Hawaii Department of Agriculture, Under Contract Number. HDOA-2006-2. pp 4154.

13. Tiwari AK, Kumar A, Raheman H. Biomass Bio-energy. 2007;31:569.

14. Karleskind A. Manuel des corps gras. 2 ed. Technique and DocumentationLavoisier; 1992.

15. Rahmouni K, Joiret S, Robbiola L, et al. Impedance Comm online. 2004;2:5.

16. Degrigny C, Argyropoulos V, Pouli P, et al. The methodological approach for the PROMET project to develop/test new non-toxic corrosion inhibitors and coatings for iron and copper alloy objects housed in mediterranean museums. Proceedings of METAL 2007. Protection of Metal Artifacts. 2007.

17. Hajjaji N, Bettach N, Hammouch H, et al. OMPIC Casablanca. Morocco patent 3069/10.2011. 2011.

18. Rodrigues J, Miranda I, Gominho J, et al. IndCrops Prod. 2013;50:828.

19. Sfaira M, Srhiri A, Keddam M, et al. Electrochim Acta. 1999;44:4395.

20. Chellouli M, Chebabe D, Dermaj A, et al. Electrochim Acta. 2016;204:50.

21. Ochoa N, Moran F, Pebere N. J Appl Electrochem. 2004;34:487.

22. Dupart M, Dabosi F, Moran F, et al. Corrosion-NACE. 1981;37:262.

23. Bonnel A, Dabosi F, Deslouis C. et al. J Electrochem Soc. 1983;130:753.

24. Cesiulis H, Tsyntsaru N, Ramanavicius A, et al. Nano-Science and Technology Book. Switzerland: Springer Int Publ; 2016.

25. Barsoukov E, Macdonald JR. Impedance Spectroscopy: Theory, Experiment, and Applications. 2nd ed. New York: Wiley Online Library; 2005.

26. Hoerlé S, Mazaudier F, Dillmann Ph, et al. Corros Sci. 2004;46:1431.

27. Cao S, Liu D, Zhang P, et al. Sci Rep. 2017;18:8773.

28. Klassen RD, Hyatt CV, Roberge PR. Canadian J Metallurgy Mater Sci. 2013;39:235.

29. Lakhrissi L, Lakhrissi B, Touir R, et al. Arabian J Chem. 2013;10: S3142S3149.

30. Amin MA, El-Rehim SSA, El-Sherbini EEF, et al. Electrochim Acta. 2007;52:3588.

31. Doubi M, Dermaj A, Erramli H, et al. Science Lib. 2013;5: $\mathrm{N}^{\circ} 130110$.

32. Es-Salah K, Keddam M, Rahmouni K, et al. Electrochim Acta. 2004;49:2771. 
33. Dobrzeniecka A, Zeradjanin A, Masa J, et al. Catalysis Today. 2013;202:55.

34. Grygar T. Collect Czech Chem Commun. 1995;60:1261.

35. Doubi M. Qualité physico-chimique des eaux naturelles et impact sur la dégradation des équipements hydromécaniques. Doctoral thesis. Kenitra, Morocco: Ibn Tofaïl University; 2016.

36. Ochoaa N, Moranb F, Pébèrea N, et al. Corros Sci. 2005;47:593.

37. Duprat M, Lafont M-C, Dabosi F. Electrochim Acta. 1985;30 :353.

38. Bouzidi D, Chetouani A, Hammouti B, et al. Int J Electrochem Sci. 2012;7:2334.

39. Deslouis C, Lafont MC, Pebere N, et al. Corros Sci. 1993;34:1567.

40. Veloz MA, I. Gonzalez I. Electrochim Acta. 2002;48:135. 